\title{
An Innovative Management of Palato Gingival Groove In A Maxillary Lateral Incisor
}

\author{
ABSTRACT: \\ A case report of discussed an inventive management of apically extending palatogingival groove causing periodontal destruction along with rationale behind this \\ technique. In this case the endodontic - periodontal lesion successfully manages without using any subgingival restorative material despite having poor \\ prognosis.
}

Keywords: Endodontic-periodontal lesion, Palatogingival groove, Subgingival restorative material

\section{Introduction:}

The palatogingival groove is a rare developmental anomaly with $2.8 \%-8.5 \%$ prevalence, located at the palatal aspect of lateral incisor due to the arrest trail of an additional root and unclear etiology. It forms due to the enwrapping of inner enamel epithelium and Hertwig's epithelial root sheath (HERS). [1,2] According to Kogon's its extension is variable from central fossa to root surface.[3] According to Ennes and Laraan mutation of hereditary systems could be mindful. [4] The oddity may be one-sided or respective. [5,6]. Likewise, the existence of a palatogingival groove has been observed in maxillary second molars.[7]

The association between palatogingival groove and localized periodontitis was first reported by Lee at al. [8] The occurrences of long funnel-shaped defect and patient's inability to keep the area clean leads to the bacterial and plaque accumulation which causes inflammation. The association of the defect along with the pulpal cavity worsen the condition and complicate the prognosis. [8-11] It is clear that depth, extension, and complexity of the groove is directly associated with localized periodontitis with the evolvement of pulp and leads to endodontic periodontal lesions.[12]

The radicular groove remains undetected until the patient became symptomatic due to pupal or periodontal

\begin{tabular}{|l|l|}
\hline \multicolumn{3}{|c|}{ Access this article online } \\
\hline $\begin{array}{l}\text { Website: } \\
\text { www.ujds.in }\end{array}$ \\
\hline $\begin{array}{l}\text { DOI: } \\
\text { https://doi.org/10.21276/10.21276/ujds.2020.6.2.18 }\end{array}$ \\
\hline
\end{tabular}

involvement. This article presents a case report of the management palatoginigval defect with an innovative approach.

\section{Case report:}

A 37-year-old male patient reported to the Outpatient Department, with a chief complaint of intermittent pain and discharge in the right upper front tooth region for 6 months. No history of trauma was given. During the clinical examination, the right maxillary lateral incisor (\#12), discolored with the presence of grade I mobility with negative vitality testing and positive to percussion. Examination on palatal aspect revealed a localized pocket of $10 \mathrm{~mm}$ depth with pus discharge from the pocket. On careful examination, a deep palatogingival groove was observed, which was extending deep into the apical region (Fig. 1A)

The right lateral incisor shows an extensive bone loss and deep periodontal probing depth. This extensive amount of bone loss along with the above findings at the age of 38 years gives a suspicion of the endodontic periodontal lesion.

${ }^{1}$ DANA SK, ${ }^{2}$ KHAN GD, ${ }^{3}$ JOY JA AND, ${ }^{4}$ KHATIB MS

${ }^{1}$ College of Dental Sciences, Amarghad, Bhavnagar, Gujarat.

${ }^{2}$ Sharavathi Dental College and Hospital, Shimoga, Karnataka.

${ }^{3}$ Consultant Endodontist, Thiruvalla, Kerala

${ }^{4}$ Peoples College of Dental Sciences \& Research Centre, Bhopal

Address for Correspondence : Dr. Dana Suchit Kanaiyalal Senior Lecturer, College of Dental Sciences, Amarghad, Bhavnagar, Gujarat E mail:suchitdana@gmail.com

Received : 27 July 2020, Published : 31 August 2020

How to cite this article: Dana, S. K., Khan, G. D., Joy, J. A., \& Khatib, M. S. (2020). An Innovative Management of Palato Gingival Groove In A Maxillary Lateral Incisor. UNIVERSITY JOURNAL OF DENTAL SCIENCES, 6(2):71-4 
After the oral prophylaxis, multiple visit endodontic treatment was performed. At first visit cleaning and shaping were performed using crown-down technique up-to apical file size 60. Root canal debridement was done using copious irrigation with $3 \% \mathrm{NaOCl}$ and calcium hydroxide dressing was given. After the one-week tooth was debrided and irrigated with 17\% EDTA and obturated with gutta-percha and $\mathrm{AH}$ plus sealer by using lateral condensation technique. (Fig. 1B)

After completion of a root canal and curettage of the deep periodontal pocket, surgery was planned. Complete extraoral and intraoral mouth disinfection was done with betadine, local anesthesia was administered (lignocaine 2\% with epinephrine 1:80,000). A crevicular incision was given in respect to \#12 (Figure 3) and the full-thickness flap was raised. A defect was curetted and cleaned and a clear groove was visible after flap reflection (Fig. 1C); and after this, the groove was corrected with a bur (Fig. 1D); and after correction, a smooth surface develops. The defect was filled with the bone graft (Nova bone putty) (Fig. 1E) followed by a resorbable barrier membrane placement (periodical) (Fig. 1F). The flap was replaced and sutures (Fig. 1G) followed by a periodontal pack (Fig. 1H).

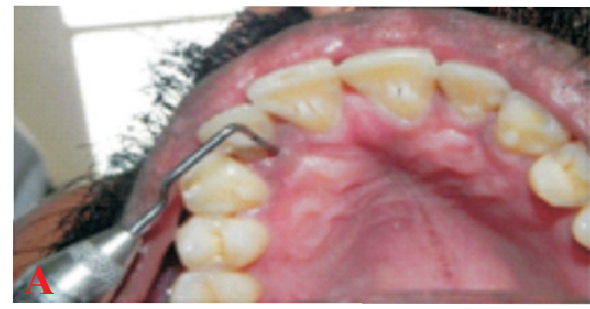

(A) Preoperative clinical;

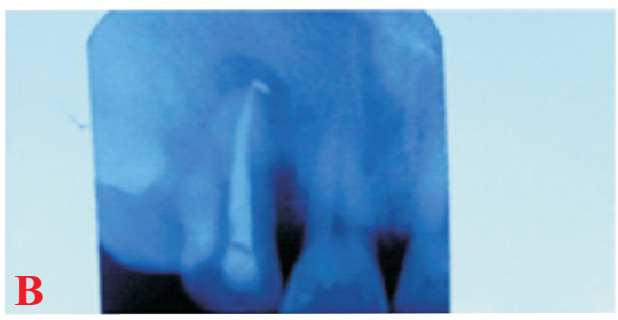

(B)After endodontic therapy;

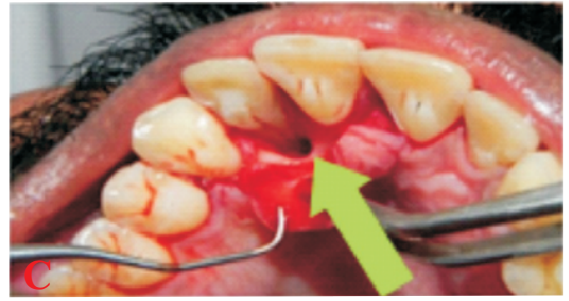

(C) Surgical opening of palatogingival groove, as marked by the arrow;

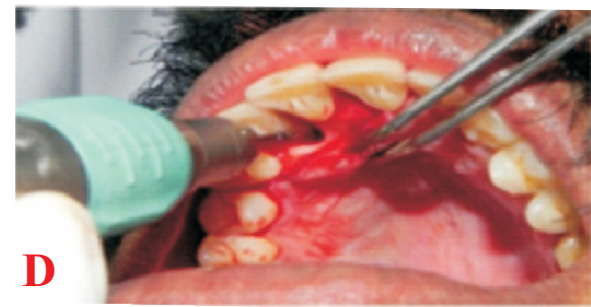

(D) Groove correction with bur

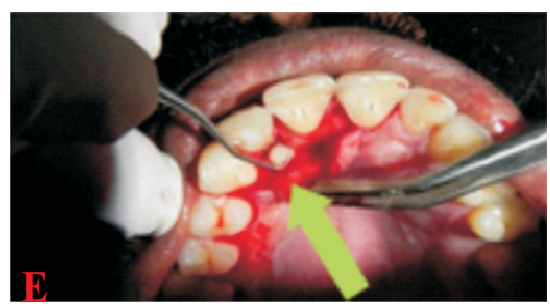

(E) bone graft placement as marked by the arrow;

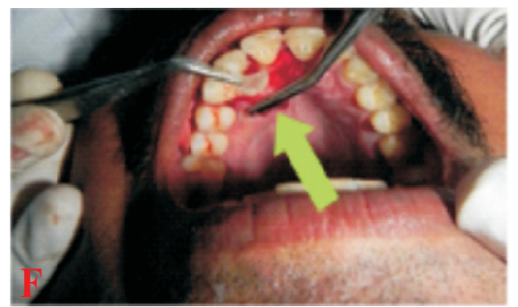

(F) Resorbable barrier membrane placement mark by arrow;

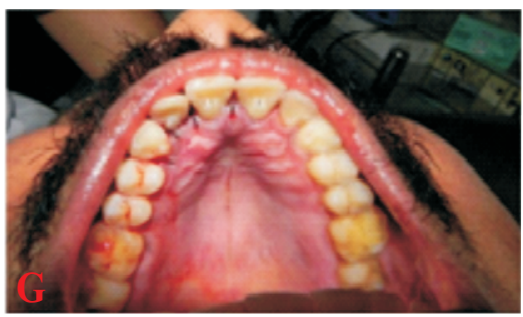

(G)Suturing;

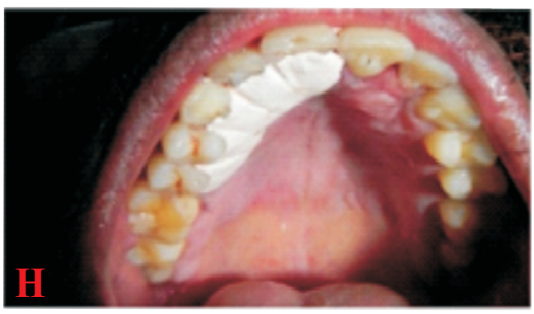

(H) Perio pack given;

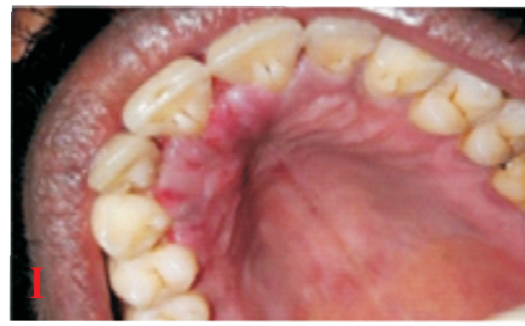

(I) postoperative 1 year; 


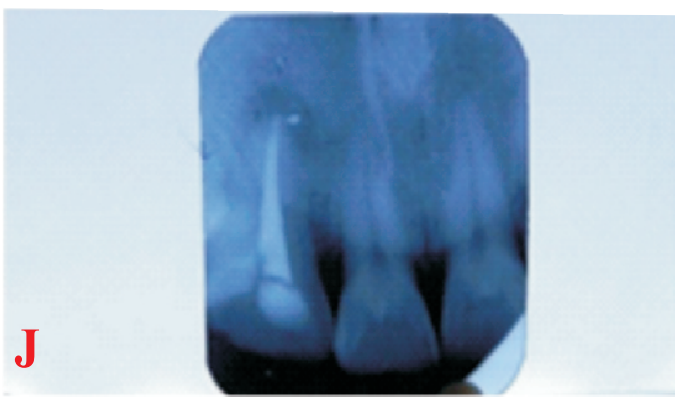

(J) postoperative 1-year radiograph.

The patient was instructed to use $0.12 \%$ chlorhexidine postsurgically twice a day for 5 weeks. He was asymptomatic postoperatively and sutures were removed after 14 days. Oral prophylaxis was performed every 3 months for 1 year. Probing depth was checked 1 year after surgery which shows pocket depth reduction to $2 \mathrm{~mm}$ in relation to right lateral incisor along with the bone formation with the absence of recession in the defect associated region. (Fig. 1I \& Fig. 1J)

\section{Discussion:}

The rationale behind the selected treatment plan was the following:

(1) Prevention of the bacterial and plaque accumulation by saucerization of the groove portion

(2) To allow the periodontal attachment with the improvement of the clinical condition

(3) To prevent further bacterial colonization removal of the coronal groove portion

Palatogingival groove act as a podium for bacterial growth due to plaque accumulation which further leads to the development of endodontic - periodontal lesion because of the communication between pulp and periodontal tissue. The radiographic picture of the palatogingival groove often leads to the misdiagnosis of vertical root fracture or extra root canal. The prognosis is depending upon the radicular extension of groove, the involvement of pulp and its location. Teeth associated with simple groove and no periodontal destruction can be treated by superficial odontoplasty and curettage of the granulation tissue as a periodontal therapy. [13-15] However for complex palatogingival groove surgical intervention along with patient encouragement for maintaining oral hygiene is required.

Dragoo et al explained the criteria for the subgingival restoration that include biocompatibility, low solubility with the absence of the microleakage, radiopacity and low coefficient of thermal expansion.[16] Various materials such as amalgam, GIC, MTA, resin cement have been used to fill the palatogingival groove. $[1,17,18]$ To date, none of the restorative material fulfills the criteria. MTA is the most biocompatible calcium silicate material available to date and also required moisture to set but get washed off easily.

If groove extension is deep or up to the apical third than surgical intervention is recommended. Various regenerative materials such as bone graft, platelet-rich plasma have been based on the size of the defects. Since decade guided tissue regeneration (GTR) has been used as a regenerative material which prevents the epithelial downwards growth and allows the growth of periodontium, cementum, and bone. McClain et al. proclaimed that combined used of graft/GTR promotes certain attachment levels. [20] In this case with the combined technique we able to achieve significantly better results than open flap debridement alone. Before treatment, the initial pocket depth was $10 \mathrm{~mm}$ which reduced to $2 \mathrm{~mm}$ after the combined therapy.

In the present case extraction was planned earlier but because the tooth is present in esthetic zone more conservative therapy was planned because replacing the tooth with an implant or fixed partial denture is more costly rather than saving it. Although the palatal surgical approach was difficult the reconstruction of the papillary zone would have been more difficult as compared to the palatal approach.

The only precautionary measurement needed that patients should abstain from smoking post-surgically because it leads to failure. [21] In the present case the success can be related to bacterial elimination and smoothing of the groove without any restorative material.

\section{Conclusion:}

Palatogingival groove is a rare anomaly that leads to the endodontic - periodontal lesion. In more complex cases it is advisable to surgically intervene. In the present case we successfully able to achieve pocket depth reduction almost 8 $\mathrm{mm}$ and an adequate amount of healing without restoring the groove with restorative materials. The treatment of complex palatoginigval grooves can be done by the interdisciplinary approach but good maintenance of oral hygiene is also required for long term success.

\section{References:}

1. Schwartz SA, Koch MA, Deas DE, Powell CA. Combined endodonticperiodontic treatment of a palatal groove: A case report. J Endod. 2006;32:573-8.

2. Simon JH, Glick DH, Frank AL. Predictable endodontic and 
periodontic failures as a result of radicular anomalies. Oral Surg Oral Med Oral Pathol. 1971;31:823-6.

3. Kogon SL. The prevalence, location and conformation of palatoradicular grooves in maxillary incisors. J Periodontol. 1986;57:231-4.

4. Ennes JP, Lara VS. Comparative morphological analysis of the root developmental groove with the palato-gingival groove. Oral Dis 2004;10:378-82.

5. Pecora JD, Sousa Neto MD, Santos TC, Saquy PC. In vitro study of the incidence of radicular grooves in maxillary incisors. Braz Dent $\mathrm{J}$ 1991;2:69-73.

6. Everett FG, Kramer GM. The disto-lingual groove in the maxillary lateral incisor: a periodontal hazard. J Periodontol 1972;43:352-61

7. Benenati FW. Maxillary second molar with two palatal canals and a palatogingival groove. J Endod 1985;11:308-10

8. Lee KW, Lee EC, Poon KY. Palato-gingival grooves in maxillary incisors: a possible predisposing factor to localised periodontal disease. Br Dent J 1968;124:14-8

9. Peikoff MD, Perry JB, Chapnick LA. Endodontic failure attributable to a complex radicular lingual groove. J Endod 1985;11:573-7.

10. Mayne JR, Martin IG. The palatal radicular groove: two case reports. Aust Dent J 1990;35:277-81

11. Robison SF, Cooley RL. Palatogingival groove lesions: recognition and treatment. Gen Dent 1988;36:340-2.

12. Simon JH, Glick DH, Frank AL. The relationship of endodontic periodontic lesion. J Periodontol. 1972;43:202-8.

13. Robison SF, Cooley RL. Palatogingival groove lesions: recognition and treatment. Gen Dent 1988;36:340-2.

14. Meister F Jr, Keating K, Gerstein H, Mayer JC. Successful treatment of a radicular lingual groove: case report. J Endod 1983;9:561-4.

15. Jeng JH, Lu HK, Hou LT. Treatment of an osseous lesion associated with a severe palato-radicular groove: a case report. J Periodontol 1992;63:708-12.

16. Dragoo MR. Resin-ionomer and hybrid-ionomer cements: part I. comparison of three materials for the treatment of subgingival root lesions. Int J Periodontics Restorative Dent. 1996;16:594-601

17. Friedman S, Goultschin J. The radicular palatal groove: a therapeutic modality. Endod Dent Traumatol 1988;4:282-6.

18. Cortellini P, Pini PG, Tonetti MS. Periodontal regeneration of human infrabony defects: I—clinical measures. J Periodontol 1993;64:254-60

19. Anderegg CR, Metzler DG. Treatment of the palato-gingival groove with guided tissue regeneration: report of 10 cases. J Periodontol 1993;64:72-4.

20. McClain PK, Schallhorn RG. Long-term assessment of combined osseous composite grafting, root conditioning, and guided tissue regeneration. Int J Periodontics Restorative Dent. 1993;13:9-27.

21. Bain CA, Moy PK. The association between the failure of dental implants and cigarette smoking. Int $\mathrm{J}$ Oral Maxillofac Implants 1993;8:609-15. 